\title{
Forecasting Financial Resources for Future Traumatic Spinal Cord Injury Care Using Simulation Modeling
}

\author{
Henry Ahn, Rachel Lewis,, Argelio Santos, ${ }^{3}$ Christiana L. Cheng, Vanessa K. Noonan, Marcel F. Dvorak, \\ Anoushka Singh, A. Gary Linassi, Sean Christie, Michael Goytan, and Derek Atkins ${ }^{9}$
}

\begin{abstract}
Survivors of traumatic spinal cord injury (tSCI) have intense healthcare needs during acute and rehabilitation care and often through the rest of life. To prepare for a growing and aging population, simulation modeling was used to forecast the change in healthcare financial resources and long-term patient outcomes between 2012 and 2032. The model was developed with data from acute and rehabilitation care facilities across Canada participating in the Access to Care and Timing project. Future population and tSCI incidence for 2012 and 2032 were predicted with data from Statistics Canada and the Canadian Institute for Health Information. The projected tSCI incidence for 2012 was validated with actual data from the Rick Hansen SCI Registry of the participating facilities. Using a medium growth scenario, in 2032, the projected median age of persons with tSCI is 57 and persons 61 and older will account for $46 \%$ of injuries. Admissions to acute and rehabilitation facilities in 2032 were projected to increase by $31 \%$ and $25 \%$, respectively. Because of the demographic shift to an older population, an increase in total population life expectancy with tSCI of $13 \%$ was observed despite a $22 \%$ increase in total life years lost to tSCI between 2012 and 2032. Care cost increased 54\%, and rest of life cost increased 37\% in 2032, translating to an additional CAD $\$ 16.4$ million. With the demographics and management of tSCI changing with an aging population, accurate projections for the increased demand on resources will be critical for decision makers when planning the delivery of healthcare after tSCI.
\end{abstract}

Keywords: forecasting; healthcare cost; incidence; simulation modeling; traumatic spinal cord injury

\section{Introduction}

$\mathbf{S}$ PINAL CORD INJURY can result in irreversible motor, sensory, and autonomic dysfunction leading to devastating impacts on the individual, both socially and economically. The intense healthcare needs for patients with traumatic spinal cord injury (tSCI) demand a number of expensive resources such as acute trauma care, rehabilitation, and also typically lifelong follow-up. It is estimated that $\sim 44,000$ individuals live with tSCI in Canada (1298 per million). ${ }^{1}$ The acute care cost during the first year of injury is estimated to be in the excess of CAD $\$ 120,000$ per patient $^{2}$; thereafter, the estimated lifetime cost for living with the injury can range from CAD $\$ 1.47$ million for patients with incomplete paraplegia to $\$ 3$ million for those with more severe $\mathrm{tSCI}^{3}$ This type of injury presents a significant economic burden to both the patient and the healthcare system as a whole.

The two major causes and populations of those injured are young men in motor vehicle accidents and older persons in falls, which were reported to account for $35 \%$ and $31 \%$ of Canadian tSCI cases, respectively. ${ }^{4} \mathrm{~A}$ recent contrasting trend toward declining rates in motor vehicle-related injuries and increasing rates in fall-related injuries, however, has been noted nationally and internationally by

\footnotetext{
${ }^{1}$ University of Toronto Spine Program, Toronto, Ontario, Canada.

${ }^{2}$ Centre for Operations Excellence, Sauder School of Business, University of British Columbia, Vancouver, British Columbia, Canada.

${ }^{3}$ Rick Hansen Institute, Vancouver, British Columbia, Canada.

${ }^{4}$ Department of Orthopaedics, University of British Columbia, Vancouver, British Columbia, Canada.

${ }^{5}$ SCI Clinical Research Unit, Toronto Western Hospital, Toronto, Ontario, Canada.

${ }^{6}$ Department of Physical Medicine and Rehabilitation, University of Saskatchewan, Saskatoon, Saskatchewan, Canada.

${ }^{7}$ Research Division of Neurosurgery, Dalhousie University, Halifax, Nova Scotia, Canada.

${ }^{8}$ Sections of Orthopedics and Neurosurgery, University of Manitoba, Winnipeg, Manitoba, Canada.

${ }^{9}$ Operations and Logistics Division, Sauder School of Business, University of British Columbia, Vancouver, British Columbia, Canada.
}

(c) Henry Ahn et al., 2017; Published by Mary Ann Liebert, Inc. This Open Access article is distributed under the terms of the Creative Commons Attribution Noncommercial License (http://creativecommons.org/licenses/by-nc/4.0/) which permits any noncommercial use, distribution, and reproduction in any medium, provided the original author(s) and the source are credited. 
several epidemiological studies, all in an effort to plan priorities for resource allocation and prevention initiatives. ${ }^{5-10}$

Consistent with the contrasting trend, the mean age of patients with tSCI has been on the rise at both the provincial and national level in Canada. In 2001, the mean age was reported to be $35.3,{ }^{11}$ 41.5 in $2004,{ }^{12} 48.5$ in $2008,{ }^{13}$ and 54.6 in $2011,{ }^{13}$ paralleling the expanding proportion of persons older than 60 years at injury as documented in reviews of the literature. ${ }^{14,15}$ The profound consequences of tSCI in older persons are projected to escalate globally over the next 20 years as the world population grows and ages. In developed nations, the population aged 60 or over is increasing at a rate of $2 \%$ annually; at this pace, the total number of those aged 60 or over will increase from 269 million to 416 million by the year 2050. ${ }^{16}$ According to this projected demographic shift, some forecasting studies based on ordinary least squares method, ${ }^{17}$ Poisson regression modeling, ${ }^{18}$ and functional data analysis ${ }^{19}$ have projected sharply increasing rates of incidence of fall-related tSCI in older persons; these projections offer insights for healthcare professionals and administrators into the estimates of SCI patient numbers and highlight the need for the treatment and care of SCI unique to older patients.

The economic burden imposed by this imminent increase of tSCI incidence among older persons has not been explored, specifically in terms of the cost that will be borne by healthcare facilities such as tSCI-specialized hospitals and rehabilitation centers, and the longterm cost given the lifelong implication of the injury. The purpose of this study is to forecast the financial resources needed to plan for such a future using a computer simulation model from the Access to Care and Timing (ACT) project. The ACT project is a multicenter study to model the continuum of tSCI care from the point of injury to acute and rehabilitation care through to community reintegration. The simulation model was developed with system level data from participating acute care and rehabilitation facilities across Canada including information on utilization, cost, and logistics specific to the facility, and with patient-level data from the Rick Hansen Spinal Cord Injury Registry (RHSCIR) ${ }^{20}$ and the National Rehabilitation Reporting System (NRS) at the Canadian Institute for Health Information $(\mathrm{CIHI}){ }^{21}$ The power and sophistication of the model derives from the use of probabilities at every stage to assign outcomes for simulated persons with tSCI according to the patient attributes such as age, gender, and injury severity, as well as system outcomes according to the specifics of the participating facility.

In this study, which was initiated in 2009 , data from primary sources and population projections were used to forecast tSCI incidence for the years 2012 and 2032 in an age-, gender-, and province-specific manner. The projected tSCI incidences were used subsequently as inputs in the simulation model to estimate outcomes on the financial resources for the system including lifetime direct and indirect healthcare costs, and long-term health outcomes including life expectancy, quality-adjusted life years, and rate of mortality. With this information on both the system and patients, we hope to demonstrate the need for sufficient healthcare facilities and trained professionals to manage the unique challenges of tSCI in the future, and the need for prevention strategies targeted at reducing the incidence of these devastating injuries.

\section{Methods}

Data sources for population projections and $\mathrm{tSCl}$ incidences

The population estimates for the years 1971 to 2009 and the population projections for the years 2010 to 2032 were obtained from the Demography Division of Statistics Canada. ${ }^{22}$ The population projection scenario chosen was M4 (medium growth) in which medium values were assumed for fertility, life expectancy, and immigration.

Records for tSCI cases identified by specific International Classification of Diseases and Related Health Problems, 10th Revision (ICD 10), external cause of injury codes (E codes) ${ }^{23}$ were obtained from the National Trauma Registry (NTR) in Discharge Abstract Database (DAD) at CIHI. ${ }^{21}$ The DAD contained records of the patients who were discharged from all acute care hospitals including those who died during admission but not those who died before admission. Data for acute admissions in Quebec were not included because their provincial trauma registry was not linked to CIHI. Information on the age and gender were collected to calculate the age- and gender-specific injury rates for each province.

\section{Traumatic SCl incidence projection}

To project provincial tSCI incidence, injury rates were applied to the population projection. To obtain outcome estimates relevant to the Incidence Forecasting Model (IFM) of the ACT Model, ${ }^{24}$ only patients with tSCI admitted to a designated SCI acute facility (RHSCIR facility) were considered, of which six facilities across Canada were included in the present study. To estimate the future tSCI admissions to a RHSCIR acute facility, the number of admissions to a RHSCIR facility was divided by the provincial injury rates of the same time range, which was then applied to the projected provincial tSCI incidence. Each facility had its own time range. All analyses were performed using SAS software, Version 9.3 of the SAS System for Windows (SAS Institute Inc., Cary, NC).

\section{Validation of $2012 \mathrm{tSCl}$ incidence projection}

At the initiation of this analysis in 2009 , projections were calculated for 2012 and 2032. In the interest of validating our projection, actual numbers of acute admissions were obtained from RHSCIR for the year 2012 and compared with the projected numbers.

\section{Forecasting healthcare costs and outcomes with ACT Modeling}

The projected tSCI admissions for the years 2012 and 2032, encoded with the age and gender distribution of patients, were used as inputs for the ACT Model. The development of the ACT Model has been described elsewhere. ${ }^{25,26}$ The outputs from the ACT Model used in this study included: system outcomes (acute length of stay [LOS], probability of rehabilitation admission, and rehabilitation LOS); patient outcomes (probability of inhospital death, life expectancy [number of years lived by the person post-tSCI], life years lost [compared with life expectancy for uninjured persons of the same age], quality-adjusted life years [QALYs, dependent on neurological level and presence of secondary complications]); and costs (inhospital care costs [based on a fixed cost for basic physician services, total number of acute and rehabilitation days, and on neurology], 3,27 and long-term care costs directly attributable to tSCI incurred in the rest of life [ROL]).

The calculation of ROL cost was dependent on life expectancy, neurological level, and functional impairment (American Spinal Injury Association [ASIA] Impairment Scale [AIS] of the International Standards of Neurological Classification of SCI [ISNCSCI] ${ }^{28}$ The 2032 cost estimates were adjusted for inflation based on the Consumer Price Index ${ }^{29}$ by applying a conservative rate of $1 \%$ annual increase in healthcare costs giving a cumulative increase of $20 \%$ between 2012 and 2032 .

Twenty replications were performed for each simulated individual. Patient level outcomes were reported at the individual patient level in which the averages of these outcomes were calculated for all individuals within one replication, then the averages and 
Table 1. Projection of Age- and Gender-Specific Admissions of Traumatic Spinal Cord Injury to Each Rick Hansen Spinal Cord Injury Registry Facility for 2012 and 2032*

\begin{tabular}{|c|c|c|c|c|c|c|c|c|c|c|c|c|}
\hline \multirow{2}{*}{$\begin{array}{l}\text { Facility } \\
\text { Year }\end{array}$} & \multicolumn{2}{|c|}{1} & \multicolumn{2}{|c|}{2} & \multicolumn{2}{|c|}{3} & \multicolumn{2}{|c|}{4} & \multicolumn{2}{|c|}{5} & \multicolumn{2}{|c|}{6} \\
\hline & 2012 & 2032 & 2012 & 2032 & 2012 & 2032 & 2012 & 2032 & 2012 & 2032 & 2012 & 2032 \\
\hline \multicolumn{13}{|l|}{ Females } \\
\hline 15 & 0.1 & 0.1 & 0.1 & 0.1 & 0.1 & 0.1 & 0.1 & 0.2 & 0.0 & 0.0 & 0.4 & 0.5 \\
\hline 16 to 30 & 1.2 & 1.2 & 1.6 & 1.7 & 1.8 & 1.9 & 2.6 & 3.0 & 0.5 & 0.4 & 7.7 & 8.3 \\
\hline 31 to 45 & 0.9 & 1.1 & 1.4 & 1.6 & 1.7 & 2.0 & 1.6 & 2.1 & 0.4 & 0.4 & 5.9 & 7.1 \\
\hline 46 to 60 & 1.2 & 1.3 & 2.1 & 2.2 & 1.5 & 1.6 & 0.8 & 1.0 & 0.6 & 0.5 & 4.0 & 4.2 \\
\hline $61+$ & 3.5 & 6.4 & 3.3 & 5.9 & 2.7 & 4.9 & 1.6 & 3.5 & 1.9 & 3.2 & 9.8 & 18.3 \\
\hline \multicolumn{13}{|l|}{ Males } \\
\hline 15 & 0.3 & 0.3 & 0.3 & 0.3 & 0.5 & 0.5 & 0.4 & 0.5 & 0.1 & 0.1 & 1.7 & 2.1 \\
\hline 16 to 30 & 4.5 & 4.7 & 4.9 & 5.2 & 7.4 & 7.8 & 7.0 & 7.7 & 2.0 & 1.8 & 29.7 & 31.5 \\
\hline 31 to 45 & 3.8 & 4.5 & 4.3 & 5.0 & 6.5 & 7.8 & 5.3 & 6.7 & 1.8 & 1.7 & 22.9 & 27.6 \\
\hline 46 to 60 & 5.9 & 6.1 & 6.8 & 7.0 & 6.2 & 6.4 & 4.9 & 6.0 & 3.3 & 2.5 & 19.9 & 21.2 \\
\hline $61+$ & 6.7 & 12.8 & 5.8 & 11.1 & 6.1 & 11.6 & 3.9 & 8.8 & 4.0 & 6.8 & 22.6 & 41.5 \\
\hline Total & 28.1 & 38.4 & 30.7 & 40.3 & 34.5 & 44.5 & 28.2 & 39.6 & 14.7 & 17.6 & 124.6 & 162.3 \\
\hline
\end{tabular}

*Each of the six participating facilities was assigned a number randomly.

standard deviations were calculated across all replications. Population level outcomes were aggregated for all the individuals from each facility. To give perspective on the increase of healthcare financial resources for tSCI care as forecasted by the simulation model, projected outcomes were presented as a percent change calculated by the outcome value obtained for 2032 minus the outcome value obtained for 2012, divided by value of 2012 .

\section{Results}

\section{Projection of $\mathrm{tSCl}$ incidence}

By 2032, injuries among persons over age 60 are projected to account for $46 \%$ of all tSCI in Canada, where the median age for the future population under the M4 scenario is projected to be 57 .

\section{Projection of $t S C l$ admissions to RHSCIR facilities}

Because the primary data source for the ACT Model was from RHSCIR acute facilities participating in the ACT project at the time of analysis, it was more applicable to analyze outcomes based on the projected tSCI admissions to the specific RHSCIR facility rather than a general provincial projection. The RHSCIR-specific projections (Table 1) that included the age and gender distribution of patients were inputted in the ACT Model. Modest increase of tSCI admissions was observed for most age groups except for the $61+$ age group that had almost twice as many projected tSCI admissions in 2032 than 2012 (Table 1).

\section{Validation of $t S C I$ admissions projection for 2012}

Compared with the projected tSCI admissions for 2012, the actual numbers of admission were close to the predicted numbers for all facilities except facility 6 where the projection was greatly overestimated (Table 2). Projections for the younger male groups were slightly higher and for the $61+$ age group of both genders were slightly lower than the actual numbers (Table 2).

\section{Prediction of healthcare costs and outcomes}

Projected outcomes for each RHSCIR facility are presented in Tables 3 and 4. Based on the future tSCI admissions to RHSCIR facilities, the ACT Model calculated an increase of $31 \%$ in acute admissions across Canada in year 2032 compared with 2012 (Table 5). The predicted average probability of inhospital death increased by $87 \%$ over the next 20 years (Table 5), implying fewer admissions to rehabilitation facilities and subsequently a smaller change in the number of admissions to rehabilitation projected for 2032 (Table 5). The change in average acute and rehabilitation LOS between 2012 and 2032 was not statistically significant.

At the patient level, the increase in average age of the simulated individuals was the leading factor driving the decrease in life expectancy and life years lost observed between 2012 and 2032. The QALYs lived at the patient level went down accordingly, and ROL costs changed negligibly (Table 4). When these outcomes were examined at the population level, however, because of the projected demographic shift to the older age group, an overall increase in life expectancy of $13 \%$ between 2012 and 2032 was observed, despite an increase in total life years lost (Table 5). Further, the increase in projected acute admissions driven by the growing and aging population directly impacted and amplified the care cost and ROL cost by $54 \%$ and $37 \%$, respectively (Table 5). The combined care cost

\section{Table 2. Differences between Actual and Projected Traumatic Spinal Cord InJury Admissions to Rick Hansen SPINAL CoRd InJury Registry FACILITIES IN 2012*}

\begin{tabular}{lrrrrrr}
\hline Facility & 1 & 2 & 3 & 4 & 5 & 6 \\
\hline Females & & & & & & \\
16 to 30 & -1 & 0 & -1 & 0 & 2 & -2 \\
31 to 45 & -1 & -1 & -1 & 1 & 0 & -2 \\
46 to 60 & 1 & 0 & -1 & 0 & 3 & -2 \\
$61+$ & 2 & 4 & 1 & 3 & -2 & -1 \\
Males & & & & & & \\
16 to 30 & 3 & -4 & -4 & -1 & 3 & -16 \\
31 to 45 & 5 & -2 & -2 & -2 & -2 & -11 \\
46 to 60 & 0 & -1 & 1 & 0 & 2 & -3 \\
$61+$ & 2 & 9 & 3 & 0 & 3 & -3 \\
Total & 9 & 1 & -1 & -3 & 7 & -33 \\
\hline
\end{tabular}

*Each of the six participating facilities was assigned a number randomly. 
Table 3. Percent Increase in Projected Outcomes of Traumatic Spinal Cord Injury between 2012 and $2032 *$

\begin{tabular}{lrrrrrr}
\hline Projected outcomes & Facility 1 & Facility 2 & Facility 3 & Facility 4 & Facility 5 & Facility 6 \\
\hline Admission to acute & $34 \%$ & $34 \%$ & $29 \%$ & $39 \%$ & $21 \%$ & $30 \%$ \\
Inhospital death & $63 \%$ & $108 \%$ & $87 \%$ & $121 \%$ & $87 \%$ & $74 \%$ \\
Admission to rehabilitation & $31 \%$ & $24 \%$ & $17 \%$ & $34 \%$ & $12 \%$ & $25 \%$ \\
\hline
\end{tabular}

*Each of the six participating facilities was assigned a number randomly.

and ROI cost was projected to be CAD \$16.4 million more for 2032 compared with 2012.

\section{Discussion}

As a novel modeling and prediction approach in the area of health research, the ACT Model was used in the present study to forecast the healthcare financial resource for future tSCI care in Canada. The direct and indirect costs of tSCI injury as well as the long-term health outcomes were calculated based on the demographic profile of the projected tSCI. The model used real data obtained from various RHSCIR facilities that accounted for specific estimates from both the patient and system level. The strength of the model lies in its ability to examine the tSCI care continuum to provide a comprehensive analysis of the entire system and capture the impact of any changes upstream and downstream within the system. It is hoped that the results from this study will provide the framework to motivate policymakers to set priorities in public health and economic investments to reduce the burden of these injuries well into the future. Given similar trends in the tSCI incidence observed worldwide, our findings may be of relevance internationally to a varying degree depending on differences in SCI management.

Our study projected a significant increase in the demands on the acute and rehabilitation resources in the next 20 years as illustrated by the increase in the associated care costs. This projected increase in cost was attributed directly to the predicted surge in the number of acute admissions that was in turn caused largely by tSCI epidemiology shifting to the older population. As this population expands with concurrent increase in life expectancy, more fall-related tSCI injuries are predicted to occur.

It is generally speculated that because the mortality rate is higher in older persons with tSCI and their projected life span with SCI is less than that of younger victims, the overall ROL cost should decline. On the contrary, this may be true at the individual level, but this interpretation does not hold true at the population level. The simulation model was able to examine the implication of the projected massive growth of the older population and found that at the population level, the combined life expectancy for all individuals with tSCI was actually projected to increase by $13 \%$, which is almost exactly mirrored in the total ROL cost and QALYs constituting an enormous portion of the health system cost in the future.

A higher burden in terms of QALYs should be expected because of the additional years lived at lower health state by the older population. The current simulated QALYs were based on injury severity and rates of complications that were not age-specific; as such, the increase in QALYs was driven mostly by the increase in life expectancy. ${ }^{25}$ Older persons with a tSCI, however, often have higher rates of complications compared with younger individuals, ${ }^{30-32}$ resulting in potentially more years lived at a lower level of health overall. Further, literature has indicated the value of a QALY may be different for the older population for which the public's willingness to pay for an additional QALY is often lower than that for the younger population. ${ }^{33,34}$

Deviations were observed in the projected tSCI admissions for 2012 when compared with actual data in the 61+ age group, the younger male groups, and for facility 6 . Actual admissions of the older age group for both genders exceeded the projection supporting the well-documented rise in tSCI incidence in older persons ${ }^{17-19}$ and fall-related tSCI being the principal etiology in older women. ${ }^{11,30}$ For the younger male groups, the actual admissions being lower than the projected numbers could be attributed to awareness and preventative efforts to reduce traffic injuries associated with these groups. ${ }^{35}$

The high 2012 projected tSCI admission for facility 6 was derived from the reportedly high percentage of provincial tSCI admitted to that RHSCIR facility during the period of study with an average of $64 \%$ compared with the average of $18 \%$ observed in other facilities. This high percentage at first glance appeared overly large because this province has other Level I/II trauma centers capable of providing definitive trauma care across the different

Table 4. Percent Change in Projected Long-Term Outcomes of Traumatic Spinal Cord Injury between 2012 and $2032 *$

\begin{tabular}{|c|c|c|c|c|c|c|}
\hline Projected outcomes & Facility 1 & Facility 2 & Facility 3 & Facility 4 & Facility 5 & Facility 6 \\
\hline \multicolumn{7}{|l|}{ Patient level } \\
\hline Life expectancy & $-16 \%$ & $-15 \%$ & $-15 \%$ & $-15 \%$ & $-25 \%$ & $-13 \%$ \\
\hline Life years lost & $-9 \%$ & $-9 \%$ & $-7 \%$ & $-5 \%$ & $-9 \%$ & $-8 \%$ \\
\hline QALYs & $-16 \%$ & $-15 \%$ & $-15 \%$ & $-15 \%$ & $-25 \%$ & $-13 \%$ \\
\hline ROL costs & $3 \%$ & $4 \%$ & $4 \%$ & $3 \%$ & $-6 \%$ & $6 \%$ \\
\hline \multicolumn{7}{|l|}{ Population level } \\
\hline Total life expectancy & $13 \%$ & $14 \%$ & $11 \%$ & $19 \%$ & $-9 \%$ & $13 \%$ \\
\hline Total life years lost & $22 \%$ & $22 \%$ & $20 \%$ & $32 \%$ & $11 \%$ & $20 \%$ \\
\hline Total QALYs & $13 \%$ & $14 \%$ & $10 \%$ & $19 \%$ & $-9 \%$ & $13 \%$ \\
\hline Total care costs & $61 \%$ & $57 \%$ & $44 \%$ & $64 \%$ & $41 \%$ & $53 \%$ \\
\hline Total ROL costs & $38 \%$ & $39 \%$ & $34 \%$ & $43 \%$ & $14 \%$ & $38 \%$ \\
\hline
\end{tabular}

QALYs, Quality-adjusted life years; ROL, rest of life.

*Each of the six participating facilities was assigned a number randomly. 


\author{
Table 5. Percent Increase in Projected Outcomes \\ of Traumatic Spinal Cord InJury Between 2012 \\ AND 2032 at The Canadian LeVel
}

\begin{tabular}{lc}
\hline Projected outcomes & $\begin{array}{c}\text { Percent } \\
\text { increase }\end{array}$ \\
\hline Admissions to acute & $31 \%$ \\
Inhospital death & $87 \%$ \\
Admissions to rehabilitation & $25 \%$ \\
Total life expectancy & $13 \%$ \\
Total life years lost & $22 \%$ \\
Total QALYs & $13 \%$ \\
Total care costs & $54 \%$ \\
Total ROL costs & $37 \%$ \\
\hline
\end{tabular}

QALYs, quality-adjusted life years; ROL, rest of life.

health regions, ${ }^{36}$ but that RHSCIR facility is the only subspecialty SCI center in the province of approximately 4.2 million, with almost all patients with SCI being transferred to the center for assessment and definitive treatment. It is also possible that this high proportion was not maintained or that the routing policies may have changed in this province for the past several years, resulting in a lower actual acute admission rate to its RHSCIR facility, with other regional hospitals handling more tSCI cases.

\section{Implications}

According to our projection, the number of admissions to a RHSCIR facility can be expected to increase by more than $30 \%$ with the most increase seen in the $61+$ age group by 2032 . Consistent with the literature on older age being associated with inhospital death after tSCI, ${ }^{4,10,31,37}$ this led to a proportional increase in the projected number of deaths during the initial acute treatment. This translated to a smaller increase in the subsequent admission to rehabilitation facilities (25\%), assuming rehabilitation admission criteria remain the same. This modest increase in rehabilitation admission would still have amplifying cost consequences because the average LOS in rehabilitation was projected to be close to 100 days compared with 34 days for the current average acute LOS.

Consistent with the long stays in rehabilitation and its associated high cost, a recent population-based cost analysis reported that the average per-person cost of rehabilitation in Ontario was found to be three times that of acute care. ${ }^{2}$ To reduce cost, there is a trend shifting care from inpatient to outpatient settings and implementing case-costing models in rehabilitation. Such practice change influenced by new policies, different payment scheme, and technology advances, all of which are unpredictable but inevitable, is difficult to account for in the simulation model. The projected LOS based on current practice and patients' clinical characteristics represents cost-saving potential and provides incentives to reduce the LOS in rehabilitation while maintaining patients' outcome, but it is unclear whether this could be achieved for this aging population.

This shift in epidemiology has wide implications for patient outcomes and healthcare resource needs. Given the physiology of older patients, they are less able to translate neurological improvements into functional recovery, ${ }^{15,37-39}$ resulting in longer hospital stays or being discharged to a continuing care institution rather than to the community. Their recovery is further complicated by age-related high number of comorbidities with pre-existing chronic conditions, ${ }^{14,40}$ high susceptibility for secondary complications, ${ }^{30,31}$ and high prevalence of degenerative disk disease. ${ }^{14}$ Not surprisingly, high number of comorbidities and old age have been found to contribute to higher rates of acute readmission after SCI. ${ }^{41,42}$ Thus, more geriatricians trained in SCI and specialized facilities will be required to manage these complex conditions in older patients.

Being injured at older age is also associated with higher inhospital death after $\mathrm{tSCI}^{37}$ as observed in Canada, ${ }^{4,31}$ United States, ${ }^{10}$ and Australia. ${ }^{18}$ The low likelihood to survive after the injury has led to an increasing trend to offer palliative treatment to patients older than 70 with a severe injury. A recent study from the Netherlands on end of life decisions in patients with tSCI showed that most of the inhospital deaths after tSCI had end of life decisions reported (63\%); and that these decisions were found associated with advanced age, comorbidities and level of SCI. ${ }^{43}$ This has timely implication in countries like Canada where end of life decisions have been subtended from other poor prognostic medical conditions and recently applied to patients with SCI.

These compelling reasons together with our cost projection analysis highlighted the need of aggressive effort to prevent tSCI in this specific older population. Prevention initiatives such as the Parachute $^{44}$ and THINK FIRST Program have contributed successfully to a decrease in hockey-related spinal injuries and trafficrelated injury rates of tSCI in North America. ${ }^{35}$ Perhaps similar strategies could be developed with an emphasis on this new demographic. It would be of great interest to use the ACT Model to analyze the potential savings and long-term benefits under a scenario where a national health goal is implemented to target a reduction of a certain percentage of tSCI cases in the older population.

\section{Limitations}

For the prediction of $\mathrm{tSCI}$ incidence, it was assumed that the rate and tendency toward sports or high-risk activities remained the same at the population level, meaning any effect from preventative initiatives was not considered. A limitation on using the NTR's hospital discharge records included the sensitivity of such records to identify SCI being between $77 \%$ and $94 \% .{ }^{4}$ For predicting future SCI admission to RHSCIR facilities, it was assumed that the proportion of interprovincial transfer would stay the same and that the routing of injured people within the province would stay the same. There could be inaccuracy in the data sources: it was possible that RHSCIR captured fewer patients with tSCI than were actually admitted, and it was also possible that RHSCIR was overreporting those who were treated by spine surgeons but did not have a tSCI.

Several assumptions were necessary to support the ACT Model. It was assumed that no changes in both the acute and rehabilitation LOS would take place between 2012 and 2032, which is not likely with increasingly more evidence showing the decline in LOS and shifting to outpatient rehabilitation. ${ }^{45}$ It was also assumed that the threshold of injury severity for hospital admission and the medical practice would remain constant, but this might be undermined by the differential care received by older patients who are reportedly more likely to have delayed treatment or be treated in nontrauma centers. ${ }^{46,47}$

The cost calculations were made under the assumption that the measures were the same in the future years as they were currently, which likely reflected an underestimation of actual costs in the future given the high cost often associated with advanced medical technology. With the imminent healthcare reform and its consequential changes in practice, the assumptions applied in the model limited the relevancy of the projections on the financial care costs to the current time. Finally, it is clear that updated RHSCIR facilityspecific measures will enhance the utility of the model, while longitudinal data collection of tSCI populations by RHSCIR will 
provide additional data necessary for more accurate long-range projections such as mortality.

\section{Conclusion}

With the demographic shift of tSCI to an aging population, increasingly more demand will be placed on acute and rehabilitation resources in the next 20 years as demonstrated by the 54\% increase in costs for inpatient care and the $37 \%$ increase in ROL care costs. This information will be critical for decision makers and clinicians to consider when planning future healthcare for tSCI to address the specific needs of this aging population in terms of their age-related complex health conditions and recovery trajectory.

\section{Acknowledgments}

The authors thank the Rick Hansen Institute RHSCIR Team (Suzanne Humphreys, Daniel Rogers, Kristen Walden, Jayson Shurgold, Jessica Eapen, Jerome Buenaventura, Tova Plashkes, Barry White, Arlene Aspinall, Cynthia Morin, and Shannon Sproule); the RHSCIR Network and the facilities who participated in this study.

This study was supported by financial contributions from the Rick Hansen Institute, the Ontario Neurotrauma Foundation, and the Government of Canada through Health Canada and Western Economic Diversification Canada.

\section{Author Disclosure Statement}

No competing financial interests exist.

\section{References}

1. Noonan, V.K., Fingas, M., Farry, A., Baxter, D., Singh, A., Fehlings, M.G., and Dvorak, M.F. (2012). Incidence and prevalence of spinal cord injury in Canada: a national perspective. Neuroepidemiology 38 , 219-226.

2. Munce, S., Wodchis, W., Guilcher, S., Couris, C., Verrier, M., Fung, K., Craven, B., and Jaglal, S. (2013). Direct costs of adult traumatic spinal cord injury in Ontario. Spinal Cord 51, 64-69.

3. Krueger, H., Noonan, V.K., Trenaman, L.M., Joshi, P., and Rivers, C.S. (2013). The economic burden of traumatic spinal cord injury in Canada. Chronic Dis. Inj. Can. 33, 113-122.

4. Pickett, G.E., Campos-Benitez, M., Keller, J.L., and Duggal, N. (2006). Epidemiology of traumatic spinal cord injury in Canada. Spine $31,799-805$.

5. Nobunaga, A.I., Go, B.K., and Karunas, R.B. (1999). Recent demographic and injury trends in people served by the Model Spinal Cord Injury Care Systems. Arch. Phys. Med. Rehabil. 80, 1372-1382.

6. Kannus, P., Niemi, S., Palvanen, M., and Parkkari, J. (2000). Continuously increasing number and incidence of fall-induced, fractureassociated, spinal cord injuries in elderly persons. Arch. Intern. Med. 160, 2145-2149.

7. Shin, J.C., Kim, D.H., Yu, S.J., Yang, H.E., and Yoon, S.Y. (2013). Epidemiologic change of patients with spinal cord injury. Ann. Rehabil. Med. 37, 50-56.

8. van den Berg, M., Castellote, J.M., Mahillo-Fernandez, I., and de Pedro-Cuesta, J. (2011). Incidence of traumatic spinal cord injury in Aragón, Spain (1972-2008). J. Neurotrauma 28, 469-477.

9. Couris, C., Guilcher, S., Munce, S., Fung, K., Craven, B., Verrier, M., and Jaglal, S. (2010). Characteristics of adults with incident traumatic spinal cord injury in Ontario, Canada. Spinal Cord 48, 39-44.

10. Jain, N.B., Ayers, G.D., Peterson, E.N., Harris, M.B., Morse, L., O'Connor, K.C., and Garshick, E. (2015). Traumatic spinal cord injury in the United States, 1993-2012. JAMA 313, 2236-2243.

11. Sekhon, L.H., and Fehlings, M.G. (2001). Epidemiology, demographics, and pathophysiology of acute spinal cord injury. Spine 26 Suppl, S2-S12.

12. Lenehan, B., Street, J., Kwon, B.K., Noonan, V., Zhang, H., Fisher, C.G., and Dvorak, M.F. (2012). The epidemiology of traumatic spinal cord injury in British Columbia, Canada. Spine 37, 321-329.
13. Burns, A.S., Yee, J., Flett, H.M., Guy, K., and Cournoyea, N. (2013). Impact of benchmarking and clinical decision making tools on rehabilitation length of stay following spinal cord injury. Spinal Cord 51, 165-169.

14. Smith, S., Purzner, T., and Fehlings, M. (2010). The epidemiology of geriatric spinal cord injury. Top. Spinal Cord Inj. Rehabil. 15, 54-64.

15. van den Berg, M.E., Castellote, J.M., Mahillo-Fernandez, I., and de Pedro-Cuesta, J. (2010). Incidence of spinal cord injury worldwide: a systematic review. Neuroepidemiology 34, 184-192.

16. United Nations, Department of Economic and Social Affairs, Population Division. (2013). World population prospects: The 2012 revision, highlights and advance tables. Working Paper No. ESA/P/WP.228.

17. Kannus, P., Palvanen, M., Niemi, S., Parkkari, J., Natri, A., Vuori, I., and Järvinen, M. (1999). Increasing number and incidence of fallinduced severe head injuries in older adults: nationwide statistics in Finland in 1970-1995 and prediction for the future. Am. J. Epidemiol. $149,143-150$.

18. O'Connor, P.J. (2005). Forecasting of spinal cord injury annual case numbers in Australia. Arch. Phys. Med. Rehabil. 86, 48-51.

19. Ullah, S., and Finch, C.F. (2010). Functional data modelling approach for analysing and predicting trends in incidence rates-an application to falls injury. Osteoporos Int. 21, 2125-2134.

20. Noonan, V.K., Kwon, B.K., Soril, L., Fehlings, M.G., Hurlbert, R.J., Townson, A., Johnson, M., and Dvorak, M.F. (2012). The Rick Hansen Spinal Cord Injury Registry (RHSCIR): a national patientregistry. Spinal Cord 50, 22-27.

21. Haas, B., Poon, V., Waller, B., Sidhom, P., and Fortin, C.M. (2011). National Trauma Registry 2011 Report: Hospitalizations for major injury in Canada, 2008-2009 data. Toronto, ON: Canadian Institute for Health Information.

22. Statistics Canada, Demography Division. (2010). Population projections for Canada, provinces and territories, 2009-2036. Catalogue no. 91-520-X. Ottawa, ON: Minister of Industry.

23. World Health Organization. (2011). International Statistical Classification of Diseases and Related Health Problems. 10th revision, edition 2010. Geneva; WHO Press.

24. Santos, A., Fallah, N., Lewis, R., Dvorak, M.F., Fehlings, M.G., Burns, A.S., Noonan, V.K., Cheng, C.L., Chan, E., Singh, A., Belanger, L.M., and Atkins, D. (2017). Methodology of the access to care and timing simulation model for traumatic spinal cord injury care. J. Neurotrauma. Epub ahead of print.

25. Noonan, V.K., Soril, L., Atkins, D., Lewis, R., Santos, A., Fehlings, M.G., Burns, A.S., Singh, A., and Dvorak, M.F. (2012). The application of operations research methodologies to the delivery of care model for traumatic spinal cord injury: the access to care and timing project. J. Neurotrauma 29, 2272-2282.

26. Santos, A., Gurling, J., Dvorak, M.F., Noonan, V.K., Fehlings, M.G., Burns, A.S., Lewis, R., Soril, L., Fallah, N., Street, J.T., Bélanger, L., Townson, A., Liang, L., and Atkins, D. (2013). Modeling the patient journey from injury to community reintegration for persons with acute traumatic spinal cord injury in a Canadian centre. PLoS One 8, e72552.

27. Dryden, D.M., Saunders, L.D., Jacobs, P., Schopflocher, D.P., Rowe, B.H., May, L.A., Yiannakoulias, N., Svenson, L.W., and Voaklander, D.C. (2005). Direct health care costs after traumatic spinal cord injury. J. Trauma 59, 464-467.

28. Kirshblum, S.C., Waring, W., Biering-Sorensen, F., Burns, S.P., Johansen, M., Schmidt-Read, M., Donovan, W., Graves, D., Jha, A., Jones, L., Mulcahey, M.J., and Krassioukov, A. (2011). Reference for the 2011 revision of the International Standards for Neurological Classification of Spinal Cord Injury. J. Spinal Cord Med. 34, 547554.

29. Statistics Canada. (2017). Table 326-0020 - Consumer Price Index, annual, CANSIM (database). Ottawa, ON: Government of Canada

30. Krassioukov, A.V, Furlan, J.C., and Fehlings, M.G. (2003). Medical co-morbidities, secondary complications, and mortality in elderly with acute spinal cord injury. J. Neurotrauma 20, 391-399.

31. Liang, H.W., Wang, Y.H., Lin, Y.N., Wang, J.D., and Jang, Y. (2001). Impact of age on the injury pattern and survival of people with cervical cord injuries. Spinal Cord 39, 375-380.

32. Güzelküçük, Ü., Demir, Y., Kesikburun, S., Yaşar, E., and Yılmaz, B. (2014). Spinal cord injury in older population in Turkey. Spinal Cord $52,850-854$.

33. Hirth, R.A., Chernew, M.E., Miller, E., Fendrick, A.M., and Weissert, W.G. (2000). Willingness to pay for a quality-adjusted life year: in search of a standard. Med. Decis. Making 20, 332-342. 
34. Donaldson, C., Baker, R., Mason, H., Jones-Lee, M., Lancsar, E., Wildman, J., Bateman, I., Loomes, G., Robinson, A., Sugden, R., Prades, J.L., Ryan, M., Shackley, P., and Smith, R. (2011). The social value of a QALY: raising the bar or barring the raise? BMC Health Serv. Res. 11: 8 .

35. Kelly, D.F., and Becker, D.P. (2001). Advances in management of neurosurgical trauma: USA and Canada. World J. Surg. 25, 1179_ 1185 .

36. Hameed, S.M., Schuurman, N., Razek, T., Boone, D., Van Heest, R., Taulu, T., Lakha, N., Evans, D.C., Brown, D.R., Kirkpatrick, A.W., Stelfox, H.T., Dyer, D., van Wijngaarden-Stephens, M., Logsetty, S., Nathens, A.B., Charyk-Stewart, T., Rizoli, S., Tremblay, L.N., Brenneman, F., Ahmed, N., Galbraith, E., Parry, N., Girotti, M.J., Pagliarello, G., Tze, N., Khwaja, K., Yanchar, N., Tallon, J.M., Trenholm, J.A., Tegart, C., Amram, O., Berube, M., Hameed, U., and Simons, R.K. (2010). Access to trauma systems in Canada. J. Trauma 69, 1350-1361.

37. Furlan, J.C., and Fehlings, M.G. (2009). The impact of age on mortality, impairment, and disability among adults with acute traumatic spinal cord injury. J. Neurotrauma 26, 1707-1717.

38. Jakob, W., Wirz, M., van Hedel, H.J., and Dietz, V. (2009). Difficulty of elderly SCI subjects to translate motor recovery- "body function" into daily living activities. J. Neurotrauma 26, 2037-2044.

39. Seel, R.T., Huang, M.E., Cifu, D.X., Kolakowsky-Hayner, S.A., and McKinley, W.O. (2001). Age-related differences in length of stays, hospitalization costs, and outcomes for an injury-matched sample of adults with paraplegia. J. Spinal Cord Med. 24, 241-250.

40. Schneider, R.C., Cherry, G., and Pantek, H. (1954). The syndrome of acute central cervical spinal cord injury; with special reference to the mechanisms involved in hyperextension injuries of cervical spine. J. Neurosurg. 11, 546-577.

41. DeVivo, M.J., Shewchuk, R.M., Stover, S.L., Black, K.J., and Go, B.K. (1992). A cross-sectional study of the relationship between age and current health status for persons with spinal cord injuries. Paraplegia 30, 820-827.

42. Jaglal, S.B., Munce, S.E., Guilcher, S.J., Couris, C.M., Fung, K., Craven, B.C., and Verrier, M. (2009). Health system factors associated with rehospitalizations after traumatic spinal cord injury: a populationbased study. Spinal Cord 47, 604-609.

43. Osterthun, R., van Asbeck, F.W., Nijendijk, J.H., and Post, M.W. (2016). In-hospital end-of-life decisions after new traumatic spinal cord injury in the Netherlands. Spinal Cord 54, 1025-1030.

44. Tator, C.H., Provvidenza, C., and Cassidy, J.D. (2009). Spinal injuries in Canadian ice hockey: an update to 2005. Clin. J. Sport Med. 19, 451-456.

45. Devivo, M.J. (2012). Epidemiology of traumatic spinal cord injury: trends and future implications. Spinal Cord 50, 365-372.

46. Ahn, H., Bailey, C.S., Rivers, C.S., Noonan, V.K., Tsai, E.C., Fourney, D.R., Attabib, N., Kwon, B.K., Christie, S.D., Fehlings, M.G., Finkelstein, J., Hurlbert, R.J., Townson, A., Parent, S., Drew, B., Chen, J., and Dvorak, M.F. (2015). Effect of older age on treatment decisions and outcomes among patients with traumatic spinal cord injury. CMAJ 187, 873-880.

47. Doumouras, A.G., Haas, B., Gomez, D., de Mestral, C., Boyes, D.M., Morrison, L.J., Craig, A.M., and Nathens, A.B. (2012). The impact of distance on triage to trauma center care in an urban trauma system. Prehosp. Emerg. Care 16, 456-462.

Address correspondence to: Vanessa K. Noonan, PhD, PT

Rick Hansen Institute 6400-818 West 10th Avenue Vancouver, British Columbia V5Z 1 M9 Canada

E-mail: vnoonan@rickhanseninstitute.org 